\title{
Ethical international recruitment
}

\section{David Skuse}

Behavioural and Brain Sciences Unit, Institute of Child Health, London WC1 1EH, UK, email: d.skuse@ich.ucl.ac.uk

$n$ the October 2004 issue of International Psychiatry (no. 6), we published special papers on the recruitment of consultant psychiatrists from lowand middle-income countries. The case for such recruitment was made by $C$ atherine Jenkins, the N HS International Fellowships Project Manager at the Department of $\mathrm{H}$ ealth, and the case against was made by David $\mathrm{N}$ detei, Salman Karim and Malik Mubbashar. N ot surprisingly, because of the role played by the College in facilitating this 'brain drain', there have been many responses - mostly supporting the views of the latter authors. Because of the importance of the topic, and the intense feelings aroused by the policy among psychiatrists in the developing world, we are pursuing the subject in January 2005. We publish here two articles written by eminent psychiatrists who provide a perspective on the issue from outside the UK, and a response from Gareth Holsgrove, Medical Education Adviser at the College.

The first article is from $\mathrm{N}$ orman Sartorius, who directly questions the validity and ethical status of the commentary on this recruitment policy provided by $C$ atherine Jenkins. The statement which has caused him particular concern (and is quoted by all three authors) concerns the response of the Indian M inister of Health and Family Welfare to a parliamentary question on the issue - to the effect that 'the overall availability of doctors in India is sufficient'. It is worth noting that the Department of $\mathrm{H}$ ealth has also explained that the government of India has indicated it has a 'surplus of nurses'. Unfortunately, it is unclear on what basis these assurances were made. However, Professor Srinivasa Murthy makes much the same point, and he goes on to add a challenge to the Royal College of Psychiatrists (UK), by asking - how can the College believe it is acting ethically by supporting the International Fellowship Programme? We turn to the response by $\mathrm{G}$ areth $\mathrm{H}$ olsgrove for an explanation. As I understand his argument, he regards the recruitment plan as 'ethical' for a variety of reasons. First, longstanding lack of strategic planning in the UK has ensured we do not have sufficient trained doctors to service our population's needs. Second, doctors in those parts of the developing world from which we recruit are underpaid, and cannot necessarily find jobs even when appropriately qualified for them. Clearly, if the placements in the UK did offer appropriate training opportunities and were time limited, much of the heat would be taken out of the debate.

\section{Ethical international recruitment - a response}

\section{Professor Norman Sartorius}

Hospitaux Universitaires de Genève, 14, Chemin Colladon, CH-1209 Geneva, Switzerland, email: mail@normansartorius.com

his note is written for two reasons: the first is to thank Drs N detei, Karim and Mubbashar for their fine article (N detei et al, 2004) and for reminding the readers of International Psychiatry of the problems arising from the 'brain drain'; and the second is to comment on the astonishing argument presented in the paper written in reply by Catherine Jenkins, of the UK Department of Health (Jenkins, 2004).

Drs N detei and Mubbashar are veterans of the small army of mental health workers that has for many years fought to establish mental health programmes in developing countries. They have chosen to stay in their respective countries (Kenya and Pakistan) and spent much of their w orking lives advocating better mental healthcare, educating students of health and other professions, providing services to the population and carrying out research. They have trained many of the overseas consultants and other senior staff now working in the UK and in other industrialised countries. I do not have the most recent figures for Kenya or Pakistan but would not be surprised to learn that most of those whom they have trained are working today in one of the developed countries. They would have good cause to feel bitter about a continuing brain drain, which is among the most important reasons for the slow development of mental health programmes in their countries. Yet their article is not emotional or aggressive: it states the facts and invites 